\title{
Kernos
}

Revue internationale et pluridisciplinaire de religion grecque antique

$14 \mid 2001$

Varia

\section{Eratóstenes contra Aristóteles: los orígenes rituales de la tragedia}

Jordi Pàmias Massana

\section{OpenEdition \\ Journals}

\section{Edición electrónica}

URL: http://journals.openedition.org/kernos/768

DOI: $10.4000 /$ kernos.768

ISSN: 2034-7871

\section{Editor}

Centre international d'étude de la religion grecque antique

\section{Edición impresa}

Fecha de publicación: 1 enero 2001

Paginación: 51-59

ISSN: 0776-3824

\section{Referencia electrónica}

Jordi Pàmias Massana, «Eratóstenes contra Aristóteles: los orígenes rituales de la tragedia », Kernos [En ligne], 14 | 2001, mis en ligne le 14 avril 2011, consulté le 02 mai 2019. URL : http:// journals.openedition.org/kernos/768; DOI : 10.4000/kernos.768 


\section{Eratóstenes contra Aristóteles: los origenes rituales de la tragedia ${ }^{*}$}

I.

Con su elegía Erígone, Eratóstenes de Cirene se sitúa en el corazón de la especulación racionalista con la que el griego de época helenística observa e interpreta su patrimonio cultural. La obra, hoy perdida, del cirenaico (un $\delta$ id

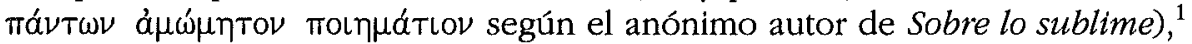
constituía, con su concatenación de episodios etiológicos, un producto propiamente helenístico en su forma y contenido. ${ }^{2}$

La elegía se basaba en un mito ático local, de Icaria. Un campesino llamado Icario y su hija Erígone reciben en su humilde choza a un Dioniso bajo forma humana. Para calmar la sed del extranjero, Erígone le ofrece un tazón de leche - irónico faux pas de la chica, puesto que no es leche lo adecuado para un huésped como Dioniso. Ante la mirada atónita de ambos, la leche se transforma en vino y unas vides crecen del suelo, manifestándose así la condición divina del visitante. En agradecimiento a la hospitalidad de Icario y su hija, Dioniso les ofrece varios odres de vino y les enseña el cultivo de la vid para que lo difundan (en recuerdo de la llegada de Dioniso, los

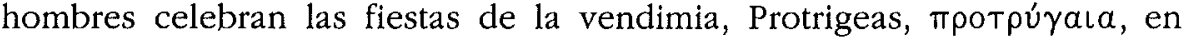
septiembre). Icario cuida de sus vides hasta que ocurre una desgracia: un

* Este artículo forma parte del trabajo "Pseudo-Eratòstenes, Catasterismes: Estudi de la tradició textual, edició, comentari i traducció" (integrado en el proyecto de investigación "Els mitògrafs grecs. Edició comentada" (DGICY'T PB96-1221), dirigido por Francesc Josep Cuartero Iborra).

1 [LONGIN.], XXXXII, 5.

2 Los principales textos fuente son: Schol. Hom. Il. XXII, 29; HYG., Astr. II, 4; NonNus, Dion. XIVVII, 1-264. La reconstrucción del poema a partir de los escasos testimonios ha sido abordada por E. MAAss, Analecta Eratosthenica, Berlin, 1883 (Pbilologische Untersuchungen, 6); por G.A. Keller, Eratosthenes und die alexandrinische Sterndichtung, Zürich, 1946, p. 29 sq.; por F. Solmsen, "Eratosthenes' Erigone: A Reconstruction", TAPhA 78 (1947), p. 252-275 [= Kleine Schriften I, Hildesheim, 1968, p. 225-248]; por R. MERKelbACH, Die Erigone des Eratostbenes, in Miscellania di studi alessandrini in memoria di A. Rostagni, Torino, 1963 (cf. ID., "Tragödie, Komödie und dionysische Kulte (Nach der Erigone des Eratosthenes)", Antaios 5 [1963/64], p. 325-343 [= Hestia und Erigone. Vorträge und Aufsätze, Stuttgart/Leipzig, 1996, p. 180-197]); y, últimamante, por A. Rosokoki, Die Erigone des Eratostbenes. Eine kommentierte Ausgabe der Fragmente, Heidelberg, 1995. 
macho cabrío (тра́ yos) irrumpe en el viñedo, pisotea las plantas y se come las hojas más lozanas. Irritado, ícaro le da muerte e invita a otros campesinos al banquete subsiguiente. Queda así instituido el sacrificio del macho cabrío en honor de Dioniso. Por otra parte, los cantos y danzas alrededor de la víctima constituyen el germen de la tragedia. Además, Icario desuella al animal y con su piel cose un odre, lo llena de aire (¿o de vino?) y lo echa al suelo para que

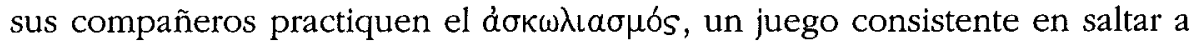
la pata coja, sin resbalar, sobre un odre engrasado. ${ }^{3}$ Después de la vendimia, Icario carga su carro con los odres de vino y se pone en marcha, acompañado de su perra Mera, para llevar a los pueblos del Ática la bebida divina - lo mismo que Triptólemo con los dones de Deméter. Un día, Icario invita a unos pastores a probar el vino y éstos, al sentir los efectos del alcohol y creyéndose envenenados, le asesinan. Cuando Erígone, gracias a las indicaciones de la perra Mera, encuentra el cadáver de su padre, se ahorca en un árbol cercano. En venganza por estas muertes, Dioniso provoca una epidemia de suicidios y todas las jóvenes de Atenas se ahorcan como Erígone. Por indicación de un oráculo, los atenienses castigan a los asesinos de Icario y establecen una fiesta en honor de su hija: se trata de las Eoras (alópa), que tienen lugar en ocasión de las Antesterias, y durante las cuales se colgaban muñecas y máscaras en los árboles para que el viento las columpiara. El poema terminaba, probablemente, con la transformación en constelación de los protagonistas: Icario se convierte en la constelación del Boyero, Erígone en la de Virgen, Mera en la del Perro.

\section{II.}

Alrededor del episodio del macho cabrío se concatenaban, según Maass, Solmsen y Merkelbach, ${ }^{4}$ nada menos que tres aitia, puesto que el relato daba cuenta del origen del sacrificio del macho cabrío ( $\tau \rho a ́ \gamma o s$ ) en honor de

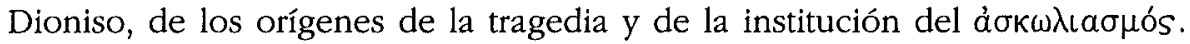
Esta secuencia está sólo atestiguada por Higino (Astr. II, 4), el cual, además, nos transmite uno de los pocos versos que conocemos de la Erígone:

qui [Icarius, sc.] cum seuisset uitem, et diligentissime administrando floridam falce fecisset, dicitur bircus in uineam se coniecisse et quae ibi tenerrima folia uideret decerpsisse. quo facto Icarum irato animo tulisse eumque interfecisse, et ex pelle eius utrem fecisse, ac uento plenum

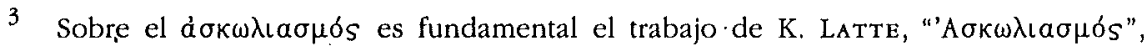
Hermes 85 (1957) p. 385-391. Cf. A. Pickard-Cambridge, The Dramatic Festivals of Athens, Oxford, $1968^{2}$ [1953], p. 45.

4 MaAss, o.c. (n. 2), p. 113; Solmsen, l.c. (n. 2), p. 243; Merkelbach, l.c. (n. 2), p. 496. Cf. también K. Meulı, "Altrömischer Maskenbrauch", MH 12 (1955), p. 211. En cambio, según Keller (o.c., p. 41) y H. Patzer (Die Anfänge der griechischen Tragödie, Wiesbaden, 1962 , p. 33), el episodio eratosténico no contenía referencia alguna a los orígenes de la tragedia. 
praeligasse, et in medium proiecisse suosque sodales circum eum saltare coegisse, itaque Eratosthenes ait:

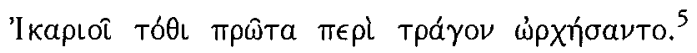

Sin embargo, el pasaje es algo incierto, porque Higino parece haber resumido drásticamente el episodio, lo cual produce una confusión que fácilmente puede inducir a error. En efecto, como ya avisó Hiller, el verso de

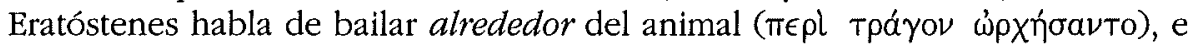
igualmente el texto de Higino (circum eum saltare coegisse), lo cual no

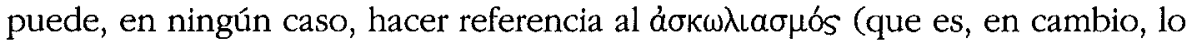
que sugieren las palabras et ex pelle eius utrem fecisse, ac uento plenum praeligasse, et in medium proiecisse.$^{6}$ Evidentemente, el autor latino ha sido víctima de una contaminación y ha creado una conflation entre dos poderosos motivos vinculados con el macho cabrío y con Dioniso: la

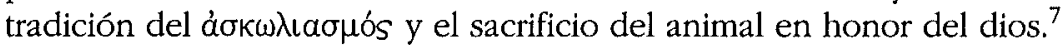

Sea como fuere, el episodio mítico descrito por Higino se ciñe estrechamente a una conocida estructura de base ritual: el animal rompe una prohibición o un tabú, lo cual sirve de motivo y pretexto para que el sacrificante supere la inhibición que le atenaza y pueda así quitarle la vida. La muerte del animal, ilícita per se, puede justificarse, a los ojos de la comunidad, a través de un sacrilegio inicial. Este motivo etiológico se reproduce analógicamente en otros mitos de caza, que tan obsesivamente poblaron la mentalidad religiosa de los griegos. Por ejemplo, en el episodio que cuenta cómo la joven Calisto, transformada en osa y perseguida por su hijo Arcas (que no ha reconocido a su madre), penetra en el santuario de Zeus Licio: la prohibición de pisar este recinto constituye el pretexto para sacrificarlos a ambos. ${ }^{8}$

5 Los manuscritos de Higino dan elkapıol. Son los editores modernos quienes han restituido 'Ikapíov, 'Ikáplot o - lo que es preferible - el locativo 'I kapıô. Por otra parte, A. Rosoкокi (o.c. [n. 2], p. 85) propone $\pi \epsilon \rho \in l s$ tpáyov donde todos los editores leen

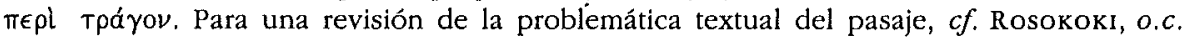
[n. 2], p. 84-86.

6 E. Hiller, Eratostbenis Carminum Reliquiae, Leipzig, 1872, p. 107-108. Cf. LatTe, l.c. (n. 3), p. 389, SOLMSEN, l.c. (n. 2), p. 243 , n. 85.

7 Aunque, según Pickard-Cambridge (o.c. [n. 3], p. 45), este juego tenía lugar en ocasión de diversos festivales y no hay que asociarlo en particular con las fiestas en

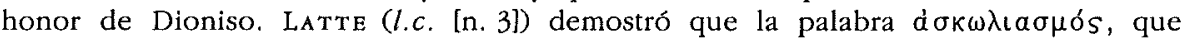
propiamente significa saltar, o saltar a la pata coja, se aplicó secundariamente a este juego en virtud de la asociación con la palabra áokós (odre). El responsable de esta combinación, según LATTE (p. 390), habría sido el mismo Eratóstenes.

8 En la versión catasterísmica del mismo Eratóstenes (Catast., l), la intervención in extremis de Zeus, que se lleva a Calisto y a Arcas a las estrellas, los salva de una muerte segura. Sin embargo, este bappy end no es sino un apéndice ajeno a la sustancia original del mito. 
Otros mecanismos de eficacia simbólica, destinados a evitar que la mancha de sangre penetre en el tejido social, incluyen acciones y gestos ritualizados como, por ejemplo, inducir a la víctima a que se acerque "voluntariamente" al lugar de inmolación, o que el animal sea obtenido mediante una compra. En caso de que la víctima sea un animal doméstico será necesaria una alienación ficticia: o bien el animal es dejado en libertad para poderlo "cazar", o bien es vendido y vuelto a comprar. Un procedimiento alternativo consiste en que el sacrificador sea alguien ajeno a la comunidad. ${ }^{9}$

Muy singularmente, el episodio del macho cabrío en el viñedo de Icario presenta una semejanza asombrosa con otro complejo mito / ritual: la muerte del buey, o ßovфóvla, celebrado en la acrópolis de Atenas en ocasión de las fiestas Dipolias. ${ }^{10}$ Este sacrificio del buey doméstico fue instituido por un campesino llamado - según las diversas fuentes - Sópatro, Díomo o Taulón. El mito cuenta que un buey se acercó al altar en el que estaban expuestas las ofrendas a los dioses para comérselas y pisotearlas. El campesino, irritado, le quitó la vida con un hacha y se dio a la fuga. Un castigo se abatió sobre Atenas, se sucedieron las sequías y las cosechas se echaron a perder, hasta que un oráculo advirtió que sólo podría corregirse la situación si el responsable era castigado. Para evitar la condena Sópatro (o Díomo, o Taulón) decidió involucrar públicamente a todos en el mismo acto, y logró convencer a los que habían ido a buscarle de que era necesario que la ciudad ejecutara un buey. Como no sabían a quién cargar con la responsabilidad, él se les ofreció para ello, estableciendo así la muerte ritual del buey. Y, en efecto, los atenienses - hasta la época de los emperadores romanos - ${ }^{11}$ practicaron escrupulosamente este rito: unos bueyes eran inducidos a rodear un altar sobre el que habían depositado un pastel. El buey que se atrevía a

9 Vid. los trabajos de W. Burkert, Homo Necans. The Antbropology of Ancient Greek Sacrificial Ritual and Mytb, transl. by Peter Bing, Berkeley/Los Angeles/London, 1983 [ed. original de 1972]; Anthropologie des religiösen Opfers. Die Sakralisierung der Gewalt, München, 1984 (Carl Friedrich von Siemens Stiftung, Tbemen, 40); "Opfer als Tötungsritual: Eine Konstante der menschlichen Kulturgeschichte?", in F. Graf (Hrsg.), Klassicbe Antike und neue Wege der Kulturwissenschaften. Symposium Karl Meuli, Basel, 11,-13. September 1991, Basel, 1992, p. 169-189.

10 La principal fuente es Teofrasto, citado por Porphyr. Abst. II, 28-30. Cf. también Schol. Arat., 132. Sobre este sacrificio, uid. las diferentes aproximaciones de K. Meuli ("Griechische Opferbräuche", in ID., Gesammelte Schriften, Thomas Gelzer (Hrsg.), Basel/Stuttgart, 1975, p. 1004 sq. [= Phyllobolia (Festscbrift Peter Von der Mübll), Basel, 1946, p. 275 sq.]), de W. Burkert (Homo Necans [n. 9], p. 136 sq.), de D. Obbink ("The Origin of Greek Sacrifice: Theophrastus on Religion and Cultural History", in W.W. Fortenbaugh, R.W. Sharples (eds.), Theophrastean Studies. On Natural Science, Physics and Metaphysics, Ethics, Religion and Rbetoric, New Brunswick/Oxford, 1988, p. 272-295) o de M.A. Katz ("Buphonia and Goring Ox: Homicide, Animal Sacrifice, and Judicial Process", in R.M. Rosen, J. Farrell (eds.), Nomodeiktes. Greek Studies in Honor of Martin Ostwald, Ann Arbor, 1993, p. 155-178).

11 Burkert, o.c. (n. 9), p. 137. 
tocar la ofrenda pagaba su sacrilegio con la muerte. Después del banquete subsiguiente tenía lugar un juicio destinado a esclarecer la responsabilidad de la muerte del animal: las mujeres portadoras del agua acusaban a los que habían afilado el hacha y el cuchillo; éstos advertían que la culpa era de quien les había ofrecido el hacha; éste, a su vez, señalaba al que había despedazado al buey, el cual cargaba las culpas sobre el cuchillo. Y no pudiendo éste hablar, era condenado por asesinato y lanzado al mar. A continuación, para completar lo que se ha venido en llamar - quizá no muy adecuadamente - comedy of innocence, ${ }^{12}$ la piel del animal, rellena de paja, era colocada ante el arado de forma que el animal recuperaba, simbólicamente, su existencia presacrificial. Este rito ha sugerido muy diversas interpretaciones - se ha visto en el buey un tótem, un $\delta a l \mu \omega \nu$ de la vegetación, el sustituto de una víctima humana e incluso al mismo Zeus -, pero sin duda la complicada secuencia ritual, en su conjunto, está destinada a que el sacrificante pueda superar su aversión a la muerte violenta y su inhibición ante el derramamiento de sangre.

Tanto Meuli como Burkert han protestado contra los intentos de aislar del rito normativo sacrificial griego la interpretación del particular sacrificio de las Bufonias. ${ }^{13} \mathrm{Y}$, en efecto, el paralelismo estructural que podemos trazar entre el episodio del macho cabrío y el complejo mito / rito de las Bufonias levanta la sospecha de que bajo el relato eratosténico subyace, igualmente, una estructura que hunde sus raíces en sólidos fundamentos rituales. Y todavía más importante: la comparación y el cotejo con el rito sacrificial de las Bufonias nos permite informar el corpus de datos sueltos que poseemos de la Erigone para coordinarlos y sistematizarlos en un único complejo mítico-ritual. ${ }^{14}$

\section{III.}

Por lo pronto, la entrada en escena del animal - el macho cabrío que irrumpe en el viñedo para destrozar las vides - es un motivo de poderoso significado ritual: la futura víctima se hace responsable de su propia muerte a través de un sacrilegio o infracción inicial (uid. supra). Incluso, en algunos

12 El término Unscbuldskomödie fue introducido por MEuLI, l.c. (n. 10), p. 1004 sq.

13 MeUli, l.c. (n. 10); BurKert, o.c. (n. 10), p. 141. Ya U. Von WILAMOWITZMoellendorf (Euripides Herakles, Erster Band, Darmstadt, 1959, p. 63 [orig. Berlin, 1889]) avisó de las analogias entre las Bufonias y el episodio eratosténico del macho cabrío.

14 E incluso nos autoriza a rellenar las lagunas e inconexiones de la tradición, aunque, lógicamente, habrá que aplicar este procedimiento con extrema prudencia: "Still more clear than the importance of ritual for the understanding of myth is the importance of myth for the history of religion, for the reconstruction and interpretation of ritual. Myth, being the 'plot', may indicate connections between rites wich are isolated in our tradition; it may provide supplements for the desperate lacunae in our knowledge" (W. Burkert, "Jason, Hypsipyle, and New Fire at Lemnos. A Study in Myth and Ritual", CQ 20 [1970], p. 14). 
rituales, es el animal quien "deliberadamente" pide su inmolación: en el templo de Hera Acrea, en Corinto, una cabra negra debía escarbar en el suelo para desenterrar un cuchillo ( $\left.\mu \alpha \chi_{\chi \alpha} \propto \rho \alpha\right)$ con el que iba a ser sacrificada. Igualmente, los relatos míticos insisten en la anuencia, e incluso complacencia, con la que el animal se acerca al altar donde ha de ser inmolado, ${ }^{15}$

Por otra parte, el texto de Higino hace referencia a la desolladura del animal y a la confección de un receptáculo (uter) con la piel de éste (Icarum irato animo tulisse eumque interfecisse, ex pelle eius utrem fecisse). A continuación, como apuntaron Eisler y Merkelbach, la piel del macho cabrío era rellenada de vino o de mosto. ${ }^{16}$ Lo cierto, no obstante, es que los manuscritos del autor latino dan uento plenum praeligasse y no uino plenum. Pero quizá no hace falta corregir uento por uino, como propone A. Rosolkoki, ${ }^{17}$ sino más bien analizar los motivos por los que el autor haya podido incurrir en este error: como hemos apuntado más arriba, ${ }^{18}$ Higino ha sido víctima de

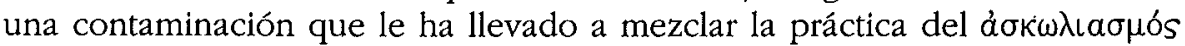
(que presupone el uso de un odre lleno de aire) con la danza alrededor del animal (circum eum saltare coegisse), o sea, el baile circular en torno de la víctima (representada mediante su piel).

La referencia al odre de vino enlaza con la antigua tradición que sitúa el sacrificio del chivo ( $\tau \rho a ́ \gamma o s)$, y el canto (áoloń) entonado en ocasión de éste, en los comienzos mismos del desarrollo del drama griego. En efecto, diversos eruditos antiguos se refieren al odre lleno de vino como premio propuesto para el vencedor de los concursos trágicos. ${ }^{19}$ Estamos ya en el núcleo mismo de la especulación etiológica helenística sobre los orígenes de la tragedia: en oposición a Aristóteles, la erudición alejandrina interpreta etimológicamente la tragedia como el "canto en ocasión del șacrificio del macho cabrío" o

15 Por ejemplo, Aeschyl., Agamemn., 1297; Porphyr., Abst. I, 25.

16 R. EISLER, Orpbisch-dionysiscbe Mysteriengedanken in der cbristlichen Antike, Leipzig, 1925 [repr. 1966], p. 268 y 277; R. Merkelbach, o.c. (n. 2), p. 497. Cf. Serv. Comm. VERG. Georg. II, 380: Libero ubique caper immolatur. quia uites, quae in bonore ipsius fuerant, ab eo comestae sunt, iratus Liber pater eum occidi fecit et ei tolli utrem, in quo mitti uinum fecit pro eius uindicta.

17 Rosokoki, o.c. (n. 2), p. 85

18 Cf. n. 6.

19 Los principales testimonios son Evantio (uid. <Euantbius de Fabula> I 2, in Aeli Donati commentum Terenti, ed. Wessner, vol. I, p. 13) y Diomedes (Grammatici Latini, ed.

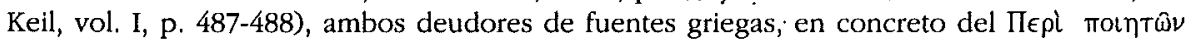
de Dídimo, según Burkert ("Greek Tragedy and Sacrificial Ritual", GRBS 7 [1966], p. 93). Cf. también Serv. Comm. Verg. Georg. II, 380-383. Por otra parte, esta tradición ha podido

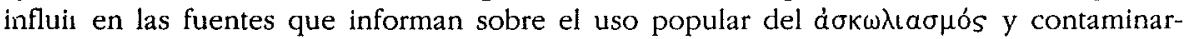
las secundariamente. Según el escoliasta de Aristófanes, los odres usados para estos

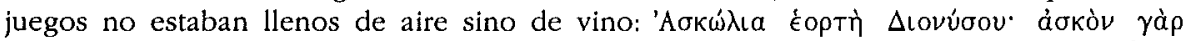

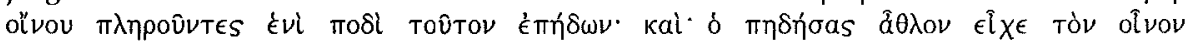
(Schol. Aristoph., Pl., 1129). 
"canto para obtener un macho cabrío como premio". ${ }^{20}$ Aunque el primer testimonio documental que sustenta esta hipótesis remonta al siglo III a.C., ${ }^{21}$

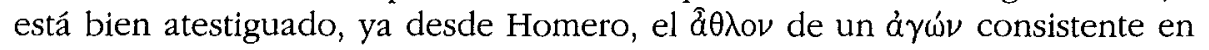
una víctima sacrificial.

Cabe considerar, pues, que la secuencia ritual del primitivo sacrificio del macho cabrío incluyese, como ocurría en las Bufonias, la restauración de su figura mediante el relleno de su piel. A través de esta práctica ritual - cuyos orígenes remontan a antiquísimos pueblos cazadores ${ }^{22}$ - queda garantizada la "resurrección" de la víctima, puesto que el animal recupera, simbólicamente, su forma prístina. ${ }^{23} \mathrm{La}$ etnografía, además, nos atestigua algunos sorprendentes usos paralelos en países centroeuropeos. ${ }^{24}$

Finalmente, para coronar la secuencia de la, llamémosla, comedy of innocence, el ejecutor del macho cabrío - Icario, en el mito - convoca a sus compañeros para rodear entre todos la víctima con una danza acompañada de cantos. Nuevo episodio, éste, de rico trasfondo ritual, puesto que el baile de los campesinos constituye una forma de circumambulatio ritualizada, estrechamente asociada con las prácticas sacrificiales - si bien es cierto que la circumambulatio, que tiene un papel destacado en el culto en Grecia, puede obedecer a otros motivos (p. ej. finalidades catárticas o apotropaicas, para solicitar una benedicción, por veneración, etc.). ${ }^{25}$ Sea como fuere, en

20 Para Aristóteles (Po., 1449a), en cambio, la tragedia deriva del drama satírico. A partir de la autoridad aristotélica, WELCKER y WILAmowitz formularon la hipótesis de que la tragedia se habría desarrollado a partir del "canto de los machos cabríos", o sea, de los danzadores disfrazados de machos cabríos.

21 En el Marmor Parium, 239 A 43 Jacoby (264/263 a.C.).

22 Meuli, l.c. (n. 10), p. 1005; cf. p. 953, 969.

23 No hace falta, pues, hacer remontar esta práctica a primitivos hábitos de viñadores, como pretende EISLER: "Damit der nach Trauben Lüsterne genug und übergenug bekäme, wurde des Bockes Haut mit Traubenmaisch prall ausgestopft, wie er die Reben niedergetrampelt hatte, wurde nun sein traubengefüllter Leib von Ikarios, dem Kelterer, getreten, bis der letzte Tropfen des Rebenblutes wieder aus ihm herausgepreßst war" (o.c. [n. 16], p. 277; $c f$. p. 266-267). Vid. también MERKELbaCH, o.c. (n. 2), p. 497.

24 EIsLer se refiere, en concreto, a las construcciones de un curioso armazón, relleno de racimos de uvas, con la forma de macho cabrio, "wie es in einigen niederösterreichischen Gegenden unter der Bezeichnung "Weiñberbock" oder "Weiñbergoas" noch bis zum Anfang des 20. Jahrhunderts angefertigt wurde" (l.c. [n. 16], p. $227 \mathrm{e}$ ilustración 105).

25 "The pattern of circumambulation rituals [is] typically coordinate with sacrifice in the eastern Mediterranean" (S.H. Lonsdale, Dance and Ritual Play in Greek Religion, Baltimore/London, 1993, p. 92). (Vid. p.ej. Apoll. RhoD., II, 700). Según este autor, la danza ritualizada cumple la función de identificar al sacrificante con la víctima: "In human ritual activities such as hunting and sacrifice the participants may take on the appearance of prey or predatory by use of mask, costume, ritual movements, or other symbolic identification [...] Ritual dance behavior is ancillary to the need for spiritual union through saćrificial and wine rituals" (p. 37). Para los distintos contextos en los que 
época histórica, los bailes de movimientos salvajes y extáticos sufrieron una evolución $y$, sobre todo en los cultos oficiales, se fueron transformando en danzas más sosegadas y solemnes. Y en cuanto a la tragedia, por ejemplo, el término $\chi \circ \rho \in \cup ́ \epsilon \iota$ se referirá, específicamente, al movimiento pausado, ordenado y acompasado del coro. ${ }^{2 b}$

\section{IV.}

Como advirtió Walter Burkert en su fundamental artículo sobre las raíces rituales de la tragedia, "no cabe esperar que se pueda reducir un fenómeno tan complejo como la tragedia griega a una única fórmula de origen." 27 En efecto, hacer derivar el teatro de un único núcleo germinal que lo contuviese esencialmente conlleva graves riesgos, porque un planteamiento mecanicista como éste no contempla la posibilidad de mutación y de reestructuración de sus componentes, de incrustación de nuevos elementos o de segregación y polarización de los existentes. ${ }^{28}$ En cualquier caso, cuando ahondamos en los indicios que nos sugiere la misma palabra $\tau \rho \alpha \gamma \omega \iota \delta i ́ a$, nos asomamos automáticamente a remotísimos estratos del desarrollo religioso de los griegos. ${ }^{29}$

Efectivamente, el examen y la interpretación del episodio de la Erígone sobre el sacrificio del macho cabrío nos ha llevado a trazar un pattern de arquitectura ritual, que demuestra que el relato eratosténico no es simplemente un artifícioso juego etiológico compuesto a espaldas de la tradición, como quería Wilamowitz. ${ }^{30}$ Creemos haber probado que los datos manejados por Eratóstenes son de estricta ascendencia tradicional, puesto que revelan un sólido anclaje ritual. Queda por explicar, sin duda, cómo ha podido desplegarse el drama ateniense a partir de prácticas semejantes o equivalentes a las descritas. Cómo, a partir de gestos de comedy of

puede darse la circumambulatio, uid. W. PAx, "Circumambulatio", RAC III (1957), col. 145.

26 "Ferner wurden im offiziellen Kultus (nicht aber bei den Mysterien u. in der Magie) die wild ekstatischen Tänze ruhiger $u$. feierlicher: der Rundtanz ging in den Rundgang über, so daß zB. in der Tragödie $\chi \circ \rho \epsilon u \in t \nu$ ein terminus technicus für die geordnet ruhig dahinschreitende Bewegung wurde" (PAx, l.c., col. 146).

27 BURKERT, l.c. (n. 19), p. 87.

28 Vid. F. Rodríguez Adrados, "Ideas metodológicas para el estudio de la evolución y sentido del teatro griego", in Simposio sobre la antigüedad clásica, Madrid, 1969.

29 Según O. SZEMERÉNYi ("The Origins of Roman Drama and Greek Tragedy", Hermes 103 [1975], p. 319 sq.), en cambio, debe ser rechazada cualquier interpretación que vincule etimológicamente la palabra $\tau \rho a \gamma \omega t \delta l a$ con el macho cabrio ( $\tau \rho a ́ \gamma o s$ ).

30 Los episodios que conforman la Erígone no son sino, según Wilamowitz, "spielend ersonnene ă̈тเа". Y concluye: "Von diesen Vorstellungen müssen wir uns losmachen, und das gelingt am sichersten, wenn wir einsehen, wo sie eigentlich herstammen und wie sie sich gebildet haben. Es sind Konstruktionen, keine Überlieferung" (o.c. [n. 13], p. 63; la cursiva es nuestra). 
innocence articulados en torno al sacrificio del macho cabrio, se ha llegado a desarrollar un género superior como es la tragedia del siglo v a.C. Describir esta emancipación plantea un auténtico reto para la filología clásica.

Universitat Autònoma de Barcelona

Jordi PÀmias Massana

Departament de Ciències de l'Antiguitat i de l'Edat Mitjana

E - 08193 Bellaterra (Barcelona) 